University of Wollongong

Research Online

$1-1-2019$

\title{
Equity in functional and health related quality of life outcomes following injury in children - a systematic review
}

\author{
Courtney Ryder \\ Flinders University, University of New South Wales \\ Tamara Mackean \\ Flinders University, University of New South Wales \\ Kate Hunter \\ University of New South Wales \\ Hayley Williams \\ University of Queensland \\ Kathleen F. Clapham \\ University of Wollongong, kclapham@uow.edu.au
}

See next page for additional authors

Follow this and additional works at: https://ro.uow.edu.au/ahsri

Research Online is the open access institutional repository for the University of Wollongong. For further information contact the UOW Library: research-pubs@uow.edu.au 


\title{
Equity in functional and health related quality of life outcomes following injury in children - a systematic review
}

\author{
Abstract \\ Injury burden is greater in children from vulnerable and disenfranchised populations. This systematic \\ review aimed to describe injury related Health Related Quality of Life (HRQOL) and function outcomes in \\ children through a health equity lens. A systematic review was conducted focussed on HRQoL and \\ functional outcomes in children ( $\leq 16$ years) following injury. We applied PRISMA-E 2012 guidelines, the \\ RTI (Research Triangle Institute) item bank for risk of bias and measured equity using PROGRESS-PLUS \\ with a narrative synthesis. Of 3013 articles, 24 were eligible for inclusion. Most assessed outcomes \\ following traumatic brain injury or burns over a 12-month period. Reduced functional and HRQoL levels \\ pre-injury or baseline, longer hospitalisation, and lower socioeconomic status were linked to poorer long- \\ term outcomes. Measures of equity in methodology, reporting and discussion were limited. Equity \\ variables, such as prior disability, were points for participant exclusion. Ethnicity was often reported only \\ in dominant cultural terms. The equity impact of injury in children remains largely unexplored. Worse \\ injury outcomes were reported in low socioeconomic families, but the relationship to other equity \\ variables was not routinely reported. This could significantly inhibit development of targeted preventative \\ programs and health care for those most in need. Injury research agendas need reform, we provide \\ guidance for research teams to assist in including equity in their research and outcomes.

\section{Publication Details} \\ C. Ryder, T. Mackean, K. Hunter, H. Williams, K. Clapham, A. J. A. Holland \& R. Ivers, "Equity in functional \\ and health related quality of life outcomes following injury in children - a systematic review", Critical \\ Public Health Online First (2019) 1-15.
}

\section{Authors}

Courtney Ryder, Tamara Mackean, Kate Hunter, Hayley Williams, Kathleen F. Clapham, Andrew J A Holland, and Rebecca Q. Ivers 


\section{Equity in Functional and Health Related Quality of Life Outcomes}

\section{Following Injury in Children - a Systematic Review}

Courtney Ryder ${ }^{\mathrm{a}, \mathrm{b}^{*} \text { ORCID ID 0000-0001-6511-1965, Tamara Mackean }}{ }^{\mathrm{a}, \mathrm{b}}$, Kate Hunter ${ }^{\mathrm{a}}$,

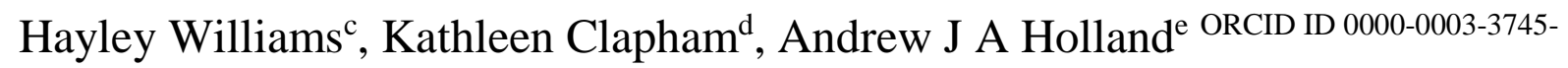
${ }^{8704}$ and Rebecca Ivers ${ }^{\mathrm{a}, \mathrm{b}, \mathrm{f}}$

${ }^{a}$ The George Institute for Global Health, UNSW, Sydney, Australia; ${ }^{b}$ Southgate Institute for Health, Society and Equity, Flinders University, Adelaide, Australia; ${ }^{c}$ Faculty of Medicine, University of Queensland, Brisbane, Australia; ${ }^{d}$ Australian Health Services Research Institute, University of Wollongong, Wollongong, Australia; ${ }^{e}$ Discipline of Child \& Adolescent Health, The Children's Hospital at Westmead Clinical School, University of

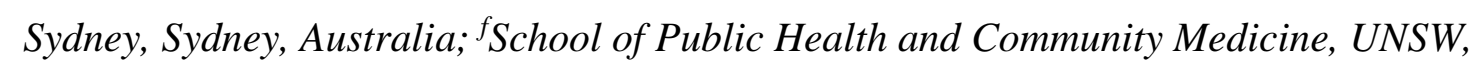
Sydney, Australia.

Correspondence: *Courtney Ryder, The George Institute for Global Health, University of New South Wales, Level 5, 1 King St, Newtown, 2042, New South Wales, Australia. Tel: +61 280524300. Fax: +61 28052 4301. E-mail: cryder@georgeinstitute.org.au 


\section{Equity in Functional and Health Related Quality of Life Outcomes}

Following Injury in Children - a Systematic Review

Injury burden is greater in children from vulnerable and disenfranchised populations. This systematic review aimed to describe injury related Health Related Quality of Life (HRQoL) and function outcomes in children through a health equity lens. A systematic review was conducted focussed on HRQoL and functional outcomes in children $(\leq 16$ years) following injury. We applied PRISMA-E 2012 guidelines, the RTI (Research Triangle Institute) item bank for risk of bias and measured equity using PROGRESSPLUS with a narrative synthesis. Of 3013 articles, 24 were eligible for inclusion. Most assessed outcomes following traumatic brain injury or burns over a 12-month period. Reduced functional and HRQoL levels pre-injury or baseline, longer hospitalisation, and lower socioeconomic status were linked to poorer long-term outcomes. Measures of equity in methodology, reporting and discussion were limited. Equity variables, such as prior disability, were points for participant exclusion. Ethnicity was often reported only in dominant cultural terms. The equity impact of injury in children remains largely unexplored. Worse injury outcomes were reported in low socioeconomic families, but the relationship to other equity variables was not routinely reported. This could significantly inhibit development of targeted preventative programs and health care for those most in need. Injury research agendas need reform, we provide guidance for research teams to assist in including equity in their research and outcomes.

Keywords: Injury; Injury Outcomes; Children; Equity; Equity Lens; 


\section{INTRODUCTION}

Injury remains a major global public health problem and the leading cause of childhood mortality and disability worldwide (Mitchell, Curtis, \& Foster, 2017; Oyegbite and Peden, 2008). On average unintentional injury is responsible for 2000 preventable child deaths globally per day (Oyegbite and Peden, 2008). Road traffic crashes, drowning and fire-related burns are the most common forms of fatal unintentional injury in children (Oyegbite and Peden, 2008). With respect to intentional injury, neglect or physical violence are the most common causes of death in children (Pinheiro, 2006). For every injury-related childhood death, millions of children are hospitalised for non-fatal trauma (Oyegbite and Peden, 2008; Pinheiro, 2006).

Injuries can result in long term loss of function, which may create occupational and social limitations and impact on individuals’ health related quality of life (HRQoL)(Anderson, Brown, Newitt, \& Hoile, 2009; Mitchell, et al., 2017; Oyegbite and Peden, 2008). The consequences of any injury can impact on the child's ability to attend and engage with school, physical and leisure activities (Mitchell, et al., 2017; Shaw and McCabe, 2008). This may be carried into adult life, impacting on future study, finding work, participating in an active social life and performing everyday activities (Anderson, et al., 2009). These impacts extend beyond the individual to the child's family or carers, causing disruption to general family life, including the emotional pain associated with a preventable condition through to the financial burden families face for ongoing care (Oyegbite and Peden, 2008; Weedon and Potterton, 2011). It is not known if these impacts are amplified by social or health inequities.

Health equity, is defined as the absence of discriminatory or avoidable disparities in health (Braveman and Gruskin, 2003; Welch et al., 2013). Equity variables, such as those of 
PROGRESS-PLUS (residence, race/ethnicity, occupation, gender, religion, education, socialcapital, socioeconomic position, age, disability, sexual orientation, other vulnerable groups), are used to describe and assess the effect social determinants of health, have in population health inequities (Kavanagh, Oliver, \& Lorenc, 2008). Globally, injury burden in children is most significant in individuals from socioeconomically disadvantaged or minority backgrounds (Covell, 2005; Oyegbite and Peden, 2008). Mortality rates in injury demonstrate clear inequities, through gender differentials, where unintentional injury rates are much higher for males, but in some injury areas, for example cases of sexual violence and burns in South Asia, girls are considerably over represented (Oyegbite and Peden, 2008; Pinheiro, 2006). Age inequities exist, with burden greatest in children under 5 years of age. Cultural inequities occur, where certain populations (i.e. First Nations children) remain over represented (Oyegbite and Peden, 2008).

The United Nations (UN) Convention on the Rights of the Child (1989), enshrines the protection of all children who experience injury, through appropriate and safe services and treatment (Oyegbite and Peden, 2008; UNICEF, 1989). To reduce injury disparities, injury research should seek to understand and address inequities in injury burden, prevention and care (Braveman and Gruskin, 2003; Welch, et al., 2013). Such research is paramount in informing government bodies and other stakeholders about where the gaps lie and the support needed to create equity. This can occur through changes to policy and resource allocation, that are cognisant of the interplay of the multiple factors of health inequities (Braveman and Gruskin, 2003; Nasser, Ueffing, Welch, \& Tugwell, 2013; Welch, et al., 2013).

Current literature suggests using an equity lens as a way for researchers to understand how equity or inequities are captured in their research and outcomes (Gahagan, Gray, \& 
Whynacht, 2015; Nasser, et al., 2013; Paradies, Harris, \& Anderson, 2008; Welch, et al., 2013; Williams and Mohammed, 2009). Despite this, health research, including the systematic review processes, has been criticised for not including an equity assessment (Welch, et al., 2013). Research which ignores inequities in health and is focussed on dominant biomedical epistemology, analysis and dissemination of study results, including systematic reviews, risks enforcing implicit bias and dominant views (Gahagan, et al., 2015; Humphery, 2001; Paradies, et al., 2008; Rigney, 2001; Welch, et al., 2013; Williams and Mohammed, 2009). This creates further marginalisation of socially disadvantaged populations and misses the opportunity to better inform health care delivery and planning (Gahagan, et al., 2015; Paradies, et al., 2008; Welch, et al., 2013; Williams and Mohammed, 2009). Understanding how current research describes equity and how it contributes to injury research agendas and outcomes is critical in creating socially accountable research which supports policy, funding and models of care which are equity inclusive and culturally safe (Nasser, et al., 2013; Welch, et al., 2013). This systematic review applies a health equity lens to describe the evidence of functional and HRQoL injury burden in children globally.

\section{METHODS}

\section{Search Strategy \& Selection Criteria}

Search terms, including MeSH and Emtree, were developed from key literature in consultation with two specialist librarians, resulting in syntax and terms outlined in Table 1 (Covell, 2005; Oyegbite and Peden, 2008). Database searches were conducted during August 2017 in MEDLINE (general and In-Process \& Non-Indexed Citations), Pubmed, EMBASE, Scopus, Cochrance (CENTRAL), and PsycINFO, focussed on peer-reviewed articles in the period 2000-2017. 
[Table 1 near here]

Key inclusion and exclusion criteria were created to capture functional and HRQoL outcomes in injured children ( $\leq 16$ years), from observational (cohort, longitudinal, follow-up and prospective) studies, Table 2. Following guidelines on injury outcome research, all studies needed to include $\geq 3$ time points (Table 2), which included baseline $<3$ months, rehabilitation/adaptive phase 1-12 months, stable 6-24 months, time points (Lyons et al., 2007; Van Beeck et al., 2007).

[Table 2 near here]

PRISMA-E 2012 guidelines were followed to carry out the review (Appendix 1). The PRISMA-E 2012 is an established framework specific to equity-focussed systematic reviews (Welch, et al., 2013). No review protocol exists for this review. Title and abstract screening against key words, inclusion and exclusion criteria was undertaken by the lead author (author). Quality assurance was undertaken through a 'blinded review’ process, where (author) reviewer assessed a 10 papers which, which passed or failed against the set criteria. The results from this blinded review were 100 percent consistent with that of (author).

Data extracted from included articles comprised: reference, study location including country, study type, setting, injury focus, sociodemographic results, outcome measures, study duration, time points (follow up), participant numbers (baseline, follow up), key findings, strengths, limitations, equity in line with the PROGRESS-Plus approach and Nasser equity lens, and risk of bias (Kavanagh, et al., 2008; Nasser, et al., 2013; Welch, et al., 2013). 


\section{Equity Focus}

Equity was assessed in study methodology, design and in outcome reporting of included studies. Guidelines recommended by the Campbell Collaboration and key Cochrane groups were adapted to include the PROGRESS-Plus headings which were used to extract relevant population and individual characteristics (Kavanagh, et al., 2008; Waters et al., 2011; Welch, et al., 2013). Further factors related to methodology and design, outlined in Appendix 2, were also recorded for consideration of equity engagement (Nasser, et al., 2013).

An additional rating was introduced for each paper based on the equity outputs from PROGRESS-Plus and Appendix 2, with a 4-part rating system, providing an overall rating of ‘equity examination,':

(1) Not evident, no consideration or discussion of equity

(2) Somewhat evident, mentioned in article in one or few areas

(3) Generally evident, equity measures outlined and discussed

(4) Highly evident, equity clearly considered.

\section{Narrative Synthesis}

A narrative synthesis approach was utilised, given the focus was on describing evidence as related to injury outcomes and equity variables. The approach used in this systematic review incorporated the three step process described by Popay et al 2006 and Petticrew et al 2006 (Petticrew and Roberts, 2006; Popay et al., 2006).

\section{Risk of Bias Assessment}


Risk of bias was assessed using the RTI (Research Triangle Institute, California, United States of America, USA) Item Bank, which has been designed to focus on evaluating risk of bias and precision in observational studies, through 29 questions focussed over 11 areas from sample definition to analysis outcome (Viswanathan and Berkman, 2012). For this systematic review the areas of: sample definition and selection, exposures, soundness of information, follow up, analysis comparability, analysis outcome and interpretation were used.

\section{RESULTS}

\section{Search Results}

The electronic database search returned 3914 records; an additional 17 were identified from reference lists. Duplicate removal resulted in 3013 articles for review. Title and abstract screening removed 2907 records, leaving 107 records for full text review. Full text review of 107 records against full criteria resulted in 24 articles being included (Appendix 1).

\section{Study characteristics}

Studies ( $\mathrm{n}=21,88 \%)$ were predominately carried out in high income countries, USA, Australia, Netherlands and Canada, see Table 3 for details. Most studies were described as prospective or longitudinal prospective ( $\mathrm{n}=17,71 \%)($ Anderson et al., 2006; Anderson, Catroppa, Morse, Haritou, \& Rosenfeld, 2001; Ding et al., 2006; Jagnoor et al., 2017; Kumaraswamy et al., 2002; McCarthy et al., 2006; Moran et al., 2011; Polinder et al., 2005; Prasad, Ewing-Cobbs, Swank, \& Kramer, 2002; Rotarescu and Ciurea, 2008; Schwartz et al., 2003; Stancin et al., 2002; Sturms et al., 2005; Yeates et al., 2012; Yeates et al., 2004).

The majority of studies focussed on traumatic brain injury (TBI)(n=14, 56\%), followed by burns and injury (both $n=3,13 \%$ ), Table 3 contains full injury details for studies. Many 
studies stratified based on injury severity, with percentage Total Body Surface Area (\%TBSA) in burns studies (Disseldorp et al., 2013; Palmieri et al., 2012; Serghiou et al., 2008) and the Glasgow Coma Scale (GCS) in TBI studies (Anderson, et al., 2006; Anderson, et al., 2001; Anderson, Morse, Catroppa, Haritou, \& Rosenfeld, 2004; Brown et al., 2016; Catroppa, Anderson, Morse, Haritou, \& Rosenfeld, 2008; Palmieri, et al., 2012; Schwartz, et al., 2003; Stancin, et al., 2002; Yeates, et al., 2004). Control groups were common in TBI studies $(60 \%, n=9)$ as either healthy or orthopaedic injury controls, matched through age, gender and socioeconomic status (SES)(Anderson, et al., 2006; Anderson, et al., 2004;

Catroppa, et al., 2008; Moran, et al., 2011; Schwartz, et al., 2003; Stancin, et al., 2002; Yeates, et al., 2012; Yeates, et al., 2004).

[Table 3 near here]

\section{Study population and recruitment}

Studies ranged in their number of recruitment sites, with one site $(n=8,33 \%)$ or four $(n=7$, 30\%) being most common; refer to Table 3 for details. Urban based hospitals were the most commonly reported recruitment site (Anderson, et al., 2006; Anderson, et al., 2001;

Anderson, Godfrey, Rosenfeld, \& Catroppa, 2012; Anderson, et al., 2004; Ding, et al., 2006; Disseldorp, et al., 2013; Jagnoor, et al., 2017; McCarthy, et al., 2006; Moran, et al., 2011; Palmieri, et al., 2012; Prasad, et al., 2002; Schneeberg et al., 2016; Schwartz, et al., 2003; Stancin, et al., 2002; Stancin et al., 2001; Sturms, et al., 2005; Yeates, et al., 2012; Yeates, et al., 2004). Eight years was the average age across all studies, with the most commonly included range at 5-16 years of age $(n=13,52 \%)$, Table 3 contains full age descriptions.

\section{Outcome measures and follow up period}


A range of different functional and HRQoL outcome measurements were used (Table 3). The most commonly reported functional outcome measure was the Vineland Adaptive Behavior Scale (VABS)(n=9, 56\%)(Anderson, et al., 2006; Anderson, et al., 2001; Anderson, et al., 2012; Anderson, et al., 2004; Catroppa, et al., 2008; Schwartz, et al., 2003; Stancin, et al., 2002; Stancin, et al., 2001; Yeates, et al., 2004). Paediatric Quality of Life Inventory (PedsQL 4.0) was the most commonly reported HRQoL outcome measure ( $\mathrm{n}=4,36 \%)($ Ding, et al., 2006; Jagnoor, et al., 2017; McCarthy, et al., 2006; Schneeberg, et al., 2016). Over half of the studies ( $n=14,56 \%$ ) contained additional assessments outside of functional and HRQoL measures, such as those for family functioning, intelligence, psychological distress, language or auditory skills, development and motor scales (Anderson, et al., 2006; Anderson, et al., 2012; Anderson, et al., 2004; Catroppa, et al., 2008; Kumaraswamy, et al., 2002; Prasad, et al., 2002; Rotarescu and Ciurea, 2008; Schneeberg, et al., 2016; Schwartz, et al., 2003; Stancin, et al., 2002; Stancin, et al., 2001; Sturms, et al., 2005; Yeates, et al., 2012; Yeates, et al., 2004). Limited studies reported on psychometric property assessment of outcome measures being used and if they had been assessed in the target population or injury population (Catroppa, et al., 2008; Ding, et al., 2006; McCarthy, et al., 2006; Moran, et al., 2011; Palmieri, et al., 2012; Polinder, et al., 2005; Serghiou, et al., 2008; Stancin, et al., 2002; Stancin, et al., 2001; Sturms, et al., 2005; Yeates, et al., 2012; Yeates, et al., 2004). One study questioned the appropriateness of the 'western-centric' HRQoL measure they used in their low to middle income Indian population (Jagnoor, et al., 2017). Another study suggested the cognitive and behavioural impacts resultant from TBI injuries, rendered their population ineffective in completing outcome measures accurately (Stancin, et al., 2002).

Most studies ran over a 12-month period ( $n=9,36 \%)$, and the majority of studies had 3-4 time points for recording outcome measures ( $n=20,83 \%)$, Table 3 contains exact follow up time 
points. After baseline recording, follow up was variable between studies, with three months common for second recordings ( $\mathrm{n}=11,46 \%)$ (Brown, et al., 2016; Ding, et al., 2006;

Disseldorp, et al., 2013; McCarthy, et al., 2006; Moran, et al., 2011; Prasad, et al., 2002; Rotarescu and Ciurea, 2008; Sturms, et al., 2005; Yeates, et al., 2004) and 12 months (n=9, 36\%) was most common for the third (Ding, et al., 2006; McCarthy, et al., 2006; Moran, et al., 2011; Prasad, et al., 2002; Schwartz, et al., 2003; Serghiou, et al., 2008; Stancin, et al., 2002; Yeates, et al., 2012; Yeates, et al., 2004). Reporting on participant numbers for each time point varied across studies, with $48 \%(n=12)$ of the studies reporting on participants at each time point (Brown, et al., 2016; Ding, et al., 2006; Disseldorp, et al., 2013; Jagnoor, et al., 2017; McCarthy, et al., 2006; Polinder, et al., 2005; Schneeberg, et al., 2016; Schwartz, et al., 2003; Serghiou, et al., 2008; Sturms, et al., 2005; Yeates, et al., 2004). While 29\% (n=7) reported attrition rates, only $8 \%$ of studies $(n=2)$ provided details on attrition rates (Schneeberg, et al., 2016; Yeates, et al., 2004).

\section{Outcomes}

Outcome measures of pre-injury HRQoL and functional, were indicators of post injury outcomes in $17 \%(n=4)$ studies, suggesting injury outcomes were influenced by premorbid burden (Anderson, et al., 2006; Anderson, et al., 2001; Anderson, et al., 2012; Moran, et al., 2011). Injury severity and complexity (such as longer hospitalisation or hand burn), affected functional and HRQoL injury outcomes negatively and were indicators for long-term disability in children impacted by injury (Anderson, et al., 2006; Anderson, et al., 2004; Catroppa, et al., 2008; McCarthy, et al., 2006; Palmieri, et al., 2012; Rotarescu and Ciurea, 2008; Schneeberg, et al., 2016; Stancin, et al., 2001; Yeates, et al., 2004). 
Most studies reported on time of recovery until 'normal' measures for functional or HRQoL outcomes. Definitions for normal outcomes varied across studies, some used pre-population measures provided by their outcome measures, whereas TBI studies mainly used recordings from matched healthy or orthopaedic injury controls.

\section{Risk of Bias}

A low risk of bias was assessed overall in each of the papers. Forms of bias included participant exclusion bias (i.e. disability or dominant language requirement), demographic and access bias (i.e. only urban recruitment sites) and attrition (i.e. higher attrition from low SES and minority backgrounds)(Anderson, et al., 2006; Anderson, et al., 2001; Anderson, et al., 2012; Anderson, et al., 2004; Brown, et al., 2016; Catroppa, et al., 2008; Ding, et al., 2006; Disseldorp, et al., 2013; Fewtrell et al., 2008; Kristman, Manno, \& Côté, 2004; McCarthy, et al., 2006; Moran, et al., 2011; Prasad, et al., 2002; Schneeberg, et al., 2016; Schwartz, et al., 2003; Stancin, et al., 2002; Stancin, et al., 2001; Sturms, et al., 2005; Yeates, et al., 2004).

\section{Equity in Study Methods}

Most studies ( $\mathrm{n}=19,76 \%)$ ranked poorly (score $<2$ ) on equity inclusion and reporting, with equity variables only mentioned infrequently in relation to study homogeneity $(n=12)$ or not at all (n=7)(Anderson, et al., 2006; Anderson, et al., 2001; Anderson, et al., 2012; Anderson, et al., 2004; Brown, et al., 2016; Catroppa, et al., 2008; Ding, et al., 2006; Disseldorp, et al., 2013; Kumaraswamy, et al., 2002; Moran, et al., 2011; Palmieri, et al., 2012; Prasad, et al., 2002; Rotarescu and Ciurea, 2008; Schneeberg, et al., 2016; Serghiou, et al., 2008; Stancin, et al., 2001; Sturms, et al., 2005; Yeates, et al., 2012; Yeates, et al., 2004). No studies reported on engagement or consultation with key stakeholders or the equity composition of research 
teams. In methodology sections, equity was addressed through standardised measures for socio-demographic information. In this area study inclusion factors excluded population groups, for instance, 59\% ( $\mathrm{n}=14)$ studies had a dominant language requirement (Anderson, et al., 2012; Anderson, et al., 2004; Brown, et al., 2016; Catroppa, et al., 2008; Ding, et al., 2006; Disseldorp, et al., 2013; McCarthy, et al., 2006; Schneeberg, et al., 2016; Schwartz, et al., 2003; Stancin, et al., 2002; Sturms, et al., 2005; Yeates, et al., 2004). Equity reporting in results focussed on the homogeneity of study participant or participant groups, with only two papers reporting lower SES and ethnic minority status as an indicator for study attrition (Moran, et al., 2011; Schwartz, et al., 2003).

\section{Equity in Study Outcomes}

Under the PROGRESS-Plus reporting as presented in Table 3, all studies reported on age and gender of children, however $63 \%(n=15)$ reported specifically on male gender in their results and not female (Anderson, et al., 2001; Anderson, et al., 2012; Anderson, et al., 2004; Catroppa, et al., 2008; Disseldorp, et al., 2013; McCarthy, et al., 2006; Moran, et al., 2011; Palmieri, et al., 2012; Schwartz, et al., 2003; Serghiou, et al., 2008; Stancin, et al., 2002; Stancin, et al., 2001; Sturms, et al., 2005; Yeates, et al., 2012; Yeates, et al., 2004). Cultural background (race/ethnicity) was reported in $42 \%(n=10)$ of articles, with these studies focussed on reporting either 'white,' 'other' or a combination of both $(n=7,70 \%)$ and these were not reported in association with study outcomes (Ding, et al., 2006; Jagnoor, et al., 2017; McCarthy, et al., 2006; Moran, et al., 2011; Palmieri, et al., 2012; Serghiou, et al., 2008; Stancin, et al., 2002; Stancin, et al., 2001; Yeates, et al., 2012; Yeates, et al., 2004). When 'other' was reported, no studies defined this category. 
SES/position was reported on $46 \%(n=11)$ of studies, generally USA based ( $n=7,64 \%)$, using a variety of tools: Duncan socioeconomic index, Daniel's Scale of Occupational Prestige or Hollingshead Four Factor Index (Anderson, et al., 2006; Anderson, et al., 2001; Anderson, et al., 2004; Ding, et al., 2006; McCarthy, et al., 2006; Moran, et al., 2011; Polinder, et al., 2005; Schwartz, et al., 2003; Stancin, et al., 2002; Sturms, et al., 2005; Yeates, et al., 2012). A further $16 \%(n=4)$ of studies elected to record socioeconomic factors but did not include these data in reporting their findings. Education level was reported in 20\% $(n=5)$ of studies, with the major focus being on maternal education level (Jagnoor, et al., 2017; McCarthy, et al., 2006; Palmieri, et al., 2012; Stancin, et al., 2002; Sturms, et al., 2005). Another 28\% $(n=7)$ of studies recorded the parental education level as an indicator of SES to compare participant demographics for homogeneity (Anderson, et al., 2001; Anderson, et al., 2004; Ding, et al., 2006; Serghiou, et al., 2008; Stancin, et al., 2001; Yeates, et al., 2012; Yeates, et al., 2004). Only two studies reported on geographical location, with one study focussing on rural Malaysian children and the other Indian children (Jagnoor, et al., 2017; Kumaraswamy, et al., 2002). Disability was a major exclusion factor for studies, with $46 \%(n=11)$ of studies inclusion criteria excluding participants with a prior form of pre-existing disability (i.e. neurological, psychiatric, mental health or developmental disorder) (Anderson, et al., 2006; Anderson, et al., 2001; Anderson, et al., 2004; Brown, et al., 2016; Catroppa, et al., 2008; Disseldorp, et al., 2013; Moran, et al., 2011; Prasad, et al., 2002; Stancin, et al., 2002; Stancin, et al., 2001; Yeates, et al., 2004). Another 38\% $(n=9)$ of studies did not report on disability in their papers (Anderson, et al., 2012; Jagnoor, et al., 2017; Palmieri, et al., 2012; Rotarescu and Ciurea, 2008; Schneeberg, et al., 2016; Schwartz, et al., 2003; Serghiou, et al., 2008; Sturms, et al., 2005; Yeates, et al., 2012). 
While the majority of studies controlled for equity measures in their population analysis (i.e. SES, gender), just over a quarter of studies $(n=7)$ factored equity measures into their overall outcome analysis (Anderson, et al., 2006; Anderson, et al., 2004; McCarthy, et al., 2006; Polinder, et al., 2005; Prasad, et al., 2002; Schwartz, et al., 2003; Yeates, et al., 2004). The predominant theme linked lower SES (i.e. family functioning, lower household resources) to poorer functional and HRQoL outcomes of injured children over time (Anderson, et al., 2006; Anderson, et al., 2004; McCarthy, et al., 2006; Polinder, et al., 2005; Schwartz, et al., 2003; Yeates, et al., 2004). SES was directly reported as a predictor for 30 month outcomes in TBI affected children (Anderson, et al., 2004). Children impacted by TBI with private health insurance or who lived in two parent household reported higher HRQoL outcomes, where reduced HRQoL outcomes occurred in families reported with poorer functioning (McCarthy, et al., 2006). Also, a higher rate of behaviour problems post-injury was reported in children with TBIs with greater socioeconomic disadvantage and in families with poorer outcomes (high distress and burden)(Schwartz, et al., 2003).

Equity focus in the discussion and conclusion sections of papers was limited in depth and focus. For instance, one study suggested that over representation of participants from certain minority groups was due to 'rambunctious' play or behavioural problems (Serghiou, et al., 2008). Two studies reported an association, between injury severity and low SES (Anderson, et al., 2006; Yeates, et al., 2004). One of these studies reported a proportional relationship between injury severity and social outcomes (as part of functional outcome measures): these outcomes were further impacted by family characteristics (i.e. resources, functioning)(Yeates, et al., 2004). The other suggested a ‘double hazard notion’ where negative outcomes transpired from the combination of injury severity and social disadvantage (Anderson, et al., 2006). In another study, girls were three times more likely to report suboptimal functioning in 
the long-term across all health outcome domains as compared to males, in this study it was demonstrated female gender and hospitalisation were independent predictors for long-term disability (Polinder, et al., 2005). Overall, there was limited discussion on the impact of equity on functional and HRQoL outcomes in children who had experienced injury.

\section{DISCUSSION}

This is the first systematic review to assess functional and HRQoL outcomes following paediatric injury through an equity lens. Results suggested that injury outcomes were influenced by baseline or pre-injury functional and HRQoL outcomes. Increased length of hospital stay, injury severity, lower SES and poorer family functioning were all associated with worse functional and HRQoL outcomes in injured children. Reporting on any correlations or associations between equity variables and HRQoL and functional outcomes was limited.

It is clear that the burden of injury is greatest in children from minority or culturally diverse backgrounds (ACIP, 2011). Despite this, the target population in this review and most child injury studies, continues to be on dominant cultures, predominantly described as 'white'. Furthermore, not speaking the dominant language is an exclusion factor in most studies included in this systematic review. These research practices effectively hide the actual burden of injury in minority populations. This in turn creates clinical and research blindness, reinforcing implicit bias and inadvertently perpetrating institutional racism (Paradies, et al., 2008; Ryder et al., 2017; Williams and Mohammed, 2009). Furthermore, it facilitates funding disparities and inhibits policy development and implementation in populations that need it the 
most (Nasser, et al., 2013; Paradies, et al., 2008; Ryder, et al., 2017; Welch, et al., 2013; Williams and Mohammed, 2009).

Addressing these deeply embedded practices requires a radical change towards appropriate approaches to research and ethics, starting with engaging with relevant community organisations, stakeholders and key researchers. Changing research practices also requires resources to empower research teams, to include minority populations through, training and study opportunities, reference and steering committees, data interpretation from routinely collected data, engaging with appropriate interpreter and or translation services, and specialised health services and professionals such as Aboriginal or migrant health workers. This review serves to highlight the need for greater awareness of inclusiveness on the part of ethics committees to encourage and facilitate culturally safe research practices, rather than create additional barriers. Conducting rigorous and high quality research in high need communities, with the community, is more meaningful and respectful, and facilitates research translation (NHMRC, 2003). It also addresses current equity gaps in research.

Studies have clearly established the link between SES and injury risk and mortality in children (ACIP, 2011; Alexandrescu, O'Brien, \& Lecky, 2009; Faelker, Pickett, \& Brison, 2000; Petridou et al., 2005; Pomerantz, Dowd, \& Buncher, 2001). Despite this knowledge, this review has identified that there is limited research examining the associations between SES and functional and HRQoL outcomes in injured children. In some studies, the latest versions for SES were not used, for example studies which used the 1983 version of Daniel's Scale of Occupational Prestige (Anderson, et al., 2006; Anderson, et al., 2012; Anderson, et al., 2004). For this research agenda to be taken further, we recommend using SES measures 
which are current, using a multidimensional concept of SES, and tailoring to population requirements where needed (i.e. ethnicity)(Alexandrescu, et al., 2009).

Our systematic review found that while boys demonstrate the greatest burden of injury, girls have a higher risk (3-fold) of long term disability following injury (Polinder, et al., 2005). Lack of gender or sex-disaggregated reporting was common in studies. Such research practice impacts on health research, through sex role socialisation and implicit bias, contributing to health access barriers and further adverse health outcomes (Chapman, Kaatz, \& Carnes, 2013; Gahagan, et al., 2015). Reporting on sex and gender assists in strengthening the present evidence base, allowing meaningful translation of clinical research into equity targeted health policies (Gahagan, et al., 2015; Ruiz-Cantero et al., 2007).

In injury based research 'disability’ has commonly been used as a way to describe participant outcomes, especially with respect to functional outcomes (Williams and Moore, 2011). In this review having a disability or mental health condition prior to a child's injury was a major exclusion factor. This practice does not allow a true representation of injury burden. Such approaches can reinforce dominant demographic profiles in injury research and influence clinical guidelines, funding, staff resourcing and policy agendas in this area (Nasser, et al., 2013; Welch, et al., 2013; Williams and Moore, 2011). Ideally, disability should not be an exclusion factor for injury study participation. Demographic information on a participant's disability and/or mental health condition can be recorded and incorporated in analyses.

We found a level of variability amongst the tools used in studies to measure functional and HRQoL outcomes in injured children. The majority of HRQoL and functional outcome tools applied had prior psychometric property assessment undertaken in dominant paediatric 
populations (i.e. USA). Some had additional assessment in specific countries (i.e. Australia, China) or specific injuries (i.e. TBI, burns). The type (i.e. validity) of psychometric property assessment was limitedly reported in studies. Impacts of limited assessment were demonstrated in one study, where a generic HRQoL was used in Indian children. They reported cultural variations in health and well-being, impacted on their HRQoL results, suggesting their generic tool inadequate for use in this population (Jagnoor, et al., 2017). The majority of studies did not consider the impact of this variability. One study, where psychometric properties had not been assessed in the target injury population, judged their study population incapable of completing their HRQoL tool due to their injury, rather than the tool being unsuitable for use in this injury population (Stancin, et al., 2002). No study undertook a comprehensive analyses of equity impact on HRQoL or functional outcomes.

Currently there are no specific guidelines for longitudinal outcome research in children. A general framework focussed on adult injury specific follow-up studies exists by Van Beeck et al (2007), but it does not capture the common nuances which present in paediatric studies, for example, parental reporting, childhood development or tool appropriateness. Further research is required to determine the most effective and appropriate functional and HRQoL measures for use in children, across a variety of injuries and populations. We recommend using more than one standardised tool for functional and HRQoL outcomes and undertaking psychometric property assessment in a small pool of the target population to confirm the suitability of each tool in the target population prior to data collection, or designing culturally validated HRQoL tools.

\section{Strengths and Limitations}


This is the first systematic review in this area to use an equity analysis lens. Observational studies were the main focus and defined as having three or more data collection points, across the following three timepoints (Table 2). Targeting studies across specific timepoints, is a strength of this study as it decreases the variability amongst timepoints (Van Beeck, et al., 2007). Observational studies did not include retrospective studies, which is a limitation in this review. While specific search syntax was designed to comprehensively search databases, some studies may have been missed. Resource limitations in this review may have introduced a level of bias. Not conducting a dual review process at all potentially stages risks introducing selection bias, random error and analyses bias into the review (McDonagh, Peterson, Raina, Chang, \& Shekelle, 2013). Excluding articles prior to 2000 and the grey literature also introduces a level of selection bias. Further, a focus on English-only articles can create language bias, although the impact may be comparatively small, however, as recent reviews have demonstrated a decline in the impact of language bias, as even research institutes where English is not the dominant language have moved to publishing in English (Cochrane, 2018). In this review 5 articles were published in English, where English is not the dominant country language. Some of the studies included in this review did have methodological limitations, for example only one study site. The review was registered with Prospero, but was not approved as the first database search had occurred.

\section{CONCLUSION}

This review found that pre-injury status, length of hospital stay, and injury severity was predictive of recovery outcomes for HRQoL and functional outcomes following injury in children. The review highlighted that few studies have explored the relationship between equity and HRQoL and functional outcomes in injured children. In the limited studies that did, children from lower socioeconomic backgrounds had poorer injury outcomes. This is 
likely to reflect associations between inequity in access to healthcare and functional and HRQoL outcomes in injured children. Furthermore, this systematic review identified that most injury research is largely undertaken with a ‘dominant biomedical research lens'. Excluding health inequities in injury outcome research, runs this risk of creating further disparities. We recommend research agendas and teams engage with minority population groups and key stakeholders, to ensure appropriate and meaningful research ensues. This should include psychometric property assessment of functional and HRQoL tools in the target population to assess suitability. Measures of disability or mental health conditions should not exclude participants. Disaggregated reporting should occur for sex or gender. Such actions can ensure that research outcomes are effective in making lasting equitable health gains for all children. 


\section{REFERENCES}

ACIP. (2011). The social determinants of Injury Canada: Atlantic Collaborative on Injury Prevention

Alexandrescu, R., O'Brien, S. J., \& Lecky, F. E. (2009). A review of injury epidemiology in the UK and Europe: some methodological considerations in constructing rates. BMC Public Health, 9(1), p 226.

Anderson, V., Brown, S., Newitt, H., \& Hoile, H. (2009). Educational, vocational, psychosocial, and quality-of-life outcomes for adult survivors of childhood traumatic brain injury. The Journal of Head Trauma Rehabilitation, 24(5), pp. 303-312.

Anderson, V., Catroppa, C., Dudgeon, P., Morse, S. A., Haritou, F., \& Rosenfeld, J. (2006). Understanding predictors of functional recovery and outcome 30 months following early childhood head injury. Neuropsychology, 20(1), pp. 42-57.

Anderson, V., Catroppa, C., Morse, S., Haritou, F., \& Rosenfeld, J. (2001). Outcome from mild head injury in young children: a prospective study. Journal of Clinical \& Experimental Neuropsychology, 23(6), pp. 705-717.

Anderson, V., Godfrey, C., Rosenfeld, J. V., \& Catroppa, C. (2012). Predictors of cognitive function and recovery 10 years after traumatic brain injury in young children. Pediatrics, 129(2), pp. e254-e261.

Anderson, V., Morse, S. A., Catroppa, C., Haritou, F., \& Rosenfeld, J. (2004). Thirty month outcome from early childhood head injury: a prospective analysis of neurobehavioural recovery. Brain, 127(12), pp. 2608-2620.

Braveman, P., \& Gruskin, S. (2003). Defining equity in health. Journal of Epidemiology \& Community Health, 57(4), pp. 254-258.

Brown, E. A., Kenardy, J., Chandler, B., Anderson, V., McKinlay, L., \& Le Brocque, R. (2016). Parent-Reported Health-Related Quality of Life in Children With Traumatic Brain Injury: A Prospective Study. Journal of Pediatric Psychology, 41(2), pp. 244-255.

Catroppa, C., Anderson, V. A., Morse, S. A., Haritou, F., \& Rosenfeld, J. V. (2008). Outcome and predictors of functional recovery 5 years following pediatric traumatic brain injury (TBI). Journal of Pediatric Psychology, 33(7), pp. 707-718.

Chapman, E. N., Kaatz, A., \& Carnes, M. (2013). Physicians and implicit bias: how doctors may unwittingly perpetuate health care disparities. Journal of General Internal Medicine, 28(11), pp. 1504-1510.

Cochrane. (2018). Reporting Biases. Retrieved from https://methods.cochrane.org/bias/reportingbiases

Covell, K. (2005). United Nations Secretary-General's Study on Violence Against Children: North American Regional Consultation. Toronto: UNICEF Canada.

Ding, R., McCarthy, M. L., Houseknecht, E., Ziegfeld, S., Knight, V. M., Korehbandi, P., . . Klotz, P. (2006). The health-related quality of life of children with an extremity fracture: a one-year follow-up study. Journal of Pediatric Orthopaedics, 26(2), pp. 157-163.

Disseldorp, L. M., Niemeijer, A. S., Van Baar, M. E., Reinders-Messelink, H. A., Mouton, L. J., \& Nieuwenhuis, M. K. (2013). How disabling are pediatric burns? Functional independence in Dutch pediatric patients with burns. Research in Developmental Disabilities, 34(1), pp. 29-39.

Faelker, T., Pickett, W., \& Brison, R. J. (2000). Socioeconomic differences in childhood injury: a population based epidemiologic study in Ontario, Canada. Injury Prevention, 6(3), pp. 203208.

Fewtrell, M. S., Kennedy, K., Singhal, A., Martin, R. M., Ness, A., Hadders-Algra, M., . . Lucas, A. (2008). How much loss to follow-up is acceptable in long-term randomised trials and prospective studies? Archives of Disease in Childhood, 93(6), pp. 458-461.

Gahagan, J., Gray, K., \& Whynacht, A. (2015). Sex and gender matter in health research: addressing health inequities in health research reporting. International Journal for Equity in Health, 14(1), p 12.

Humphery, K. (2001). Dirty questions: Indigenous health and 'Western research'. Australian and New Zealand Journal of Public Health, 25(3), pp. 197-202. 
Jagnoor, J., Prinja, S., Christou, A., Baker, J., Gabbe, B., \& Ivers, R. (2017). Health-related quality of life and function after paediatric injuries in India: a longitudinal study. International Journal of Environmental Research and Public Health, 14(10), pp. 1-12.

Kavanagh, J., Oliver, S., \& Lorenc, T. (2008). Reflections on developing and using PROGRESS-Plus. Equity Update, 2(1), pp. 1-3.

Kristman, V., Manno, M., \& Côté, P. (2004). Loss to follow-up in cohort studies: how much is too much? European Journal of Epidemiology, 19(8), pp. 751-760.

Kumaraswamy, N., Naziah, A., Abdullah, J., Ariff, M. A. R., Abdullah, M. R., \& Ghazaime, G. (2002). Outcome of children with traumatic brain injury in rural Malaysia. Journal of Clinical Neuroscience, 9(3), pp. 251-255.

Lyons, R. A., Towner, E. E., Kendrick, D., Christie, N., Brophy, S., Phillips, C. J., . . Sleney, J. (2007). The UK Burden of Injury Study-a protocol. BMC Public Health, 7(1), p 317.

McCarthy, M. L., MacKenzie, E. J., Durbin, D. R., Aitken, M. E., Jaffe, K. M., Paidas, C. N., . . . Ding, R. (2006). Health-related quality of life during the first year after traumatic brain injury. Archives of Pediatrics and Adolescent Medicine, 160(3), pp. 252-260.

McDonagh, M., Peterson, K., Raina, P., Chang, S., \& Shekelle, P. (2013). Avoiding Bias in Selecting Studies Rockville, MD: Agency for Healthcare Research and Quality.

Mitchell, R., Curtis, K., \& Foster, K. (2017). A 10-year review of the characteristics and health outcomes of injury-related hospitalisations of children in Australia Sydney: University of Sydney.

Moran, L. M., Taylor, H. G., Rusin, J., Bangert, B., Dietrich, A., Nuss, K. E., . . Yeates, K. O. (2011). Quality of life in pediatric mild traumatic brain injury and its relationship to postconcussive symptoms. Journal of Pediatric Psychology, 37(7), pp. 736-744.

Nasser, M., Ueffing, E., Welch, V., \& Tugwell, P. (2013). An equity lens can ensure an equityoriented approach to agenda setting and priority setting of Cochrane Reviews. Journal of clinical epidemiology, 66(5), pp. 511-521.

NHMRC. (2003). Values and ethics: Guidelines for ethical conduct in Aboriginal and Torres Strait Islander health research. Retrieved from https://www.nhmrc.gov.au/

Oyegbite, K., \& Peden, M. M. (2008). World report on child injury prevention. Retrieved from http://www.who.int/

Palmieri, T. L., Nelson-Mooney, K., Kagan, R. J., Stubbs, T. K., Meyer 3rd, W. J., Herndon, D. N., . . . Multi-Center Benchmarking Study Working, G. (2012). Impact of hand burns on healthrelated quality of life in children younger than 5 years. The Journal of Trauma and Acute Care Surgery, 73(3), pp. S197-S204.

Paradies, Y., Harris, R., \& Anderson, I. (2008). The impact of racism on Indigenous health in Australia and Aotearoa: Towards a research agenda Darwin: Cooperative Research Centre for Aboriginal Health.

Petridou, E., Anastasiou, A., Katsiardanis, K., Dessypris, N., Spyridopoulos, T., \& Trichopoulos, D. (2005). A prospective population based study of childhood injuries: the Velestino town study. The European Journal of Public Health, 15(1), pp. 9-14.

Petticrew, M., \& Roberts, H. (2006). Systematic Reviews in the Social Sciences: A Practical Guide Oxford: Blackwell.

Pinheiro, P. S. (2006). World report on violence against children. Retrieved from http://www.unicef.org/

Polinder, S., Meerding, W. J., Toet, H., Mulder, S., Essink-Bot, M. L., \& van Beeck, E. F. (2005). Prevalence and prognostic factors of disability after childhood injury. Pediatrics, 116(6), pp. e810-e817.

Pomerantz, W. J., Dowd, M. D., \& Buncher, C. R. (2001). Relationship between socioeconomic factors and severe childhood injuries. Journal of Urban Health, 78(1), pp. 141-151.

Popay, J., Roberts, H., Sowden, A., Petticrew, M., Arai, L., Rodgers, M., .. . Duffy, S. (2006). Guidance on the conduct of narrative synthesis in systematic reviews. A product from the ESRC methods programme. University of Lancaster. UK:

Prasad, M. R., Ewing-Cobbs, L., Swank, P. R., \& Kramer, L. (2002). Predictors of outcome following traumatic brain injury in young children. Pediatric Neurosurgery, 36(2), pp. 64-74. 
Rigney, L. I. (2001). A first perspective of Indigenous Australian participation in science: Framing Indigenous research towards Indigenous Australian intellectual sovereignty. Kaurna Higher Education Journal, 7, pp. 1-13.

Rotarescu, V., \& Ciurea, A. V. (2008). Quality of life in children after mild head injury. Journal of Medicine \& Life, 1(3), pp. 307-322.

Ruiz-Cantero, M. T., Vives-Cases, C., Artazcoz, L., Delgado, A., Calvente, M. d. M. G., Miqueo, C., . . . Ruiz, I. (2007). A framework to analyse gender bias in epidemiological research. Journal of Epidemiology \& Community Health, 61(2), pp. ii46-ii53.

Ryder, C., Mackean, T., Ullah, S., Burton, H., Halls, H., McDermott, D., \& Edmondson, W. (2017). Development and Validation of a Questionnaire to Measure Attitude change in Health Professionals after Completion of an Aboriginal Health and Cultural Safety Training Programme. The Australian Journal of Indigenous Education, pp. 1-15.

Schneeberg, A., Ishikawa, T., Kruse, S., Zallen, E., Mitton, C., Bettinger, J. A., \& Brussoni, M. (2016). A longitudinal study on quality of life after injury in children. Health and Quality of Life Outcomes, 14(1), pp. 120-131.

Schwartz, L., Taylor, H. G., Drotar, D., Yeates, K. O., Wade, S. L., \& Stancin, T. (2003). Long-term behavior problems following pediatric traumatic brain injury: prevalence, predictors, and correlates. Journal of Pediatric Psychology, 28(4), pp. 251-263.

Serghiou, M. H., Rose, M. W., Pidcock, F. S., Esselman, P. C., Engrav, L. H., Kowalske, K. J., \& Lezotte, D. C. (2008). The WeeFIM [R] instrument--a paediatric measure of functional independence to predict longitudinal recovery of paediatric burn patients. Developmental Neurorehabilitation, 11(1), pp. 39-50.

Shaw, S. R., \& McCabe, P. C. (2008). Hospital-to-school transition for children with chronic illness: Meeting the new challenges of an evolving health care system. Psychology in the Schools, 45(1), pp. 74-87.

Stancin, T., Drotar, D., Taylor, H. G., Yeates, K. O., Wade, S. L., \& Minich, N. M. (2002). Healthrelated quality of life of children and adolescents after traumatic brain injury. Pediatrics, 109(2), pp. e34-e42.

Stancin, T., Kaugars, A. S., Thompson, G. H., Taylor, H. G., Yeates, K. O., Wade, S. L., \& Drotar, D. (2001). Child and family functioning 6 and 12 months after a serious pediatric fracture. Journal of Trauma-Injury Infection \& Critical Care, 51(1), pp. 69-76.

Sturms, L. M., van der Sluis, C. K., Stewart, R. E., Groothoff, J. W., Jan ten Duis, H., \& Eisma, W. H. (2005). A prospective study on paediatric traffic injuries: Health-related quality of life and post-traumatic stress. Clinical Rehabilitation, 19(3), pp. 312-322.

UNICEF. (1989). Convention on the Rights of the Child. Retrieved from https://www.unicef.org/crc/.

Van Beeck, E. F., Larsen, C. F., Lyons, R. A., Meerding, W.-J., Mulder, S., \& Essink-Bot, M.-L. (2007). Guidelines for the conduction of follow-up studies measuring injury-related disability. Journal of Trauma and Acute Care Surgery, 62(2), pp. 534-550.

Viswanathan, M., \& Berkman, N. D. (2012). Development of the RTI item bank on risk of bias and precision of observational studies. Journal of clinical epidemiology, 65(2), pp. 163-178.

Waters, E., de Silva-Sanigorski, A., Burford, B. J., Brown, T., Campbell, K. J., Gao, Y., . . . Summerbell, C. D. (2011). Interventions for preventing obesity in children. The Cochrane Database Systematic Reviews, CD001871(12)

Weedon, M., \& Potterton, J. (2011). Socio-economic and clinical factors predictive of paediatric quality of life post burn. Burns, 37(4), pp. 572-579.

Welch, V., Petticrew, M., Tugwell, P., Moher, D., O'Neill, J., Waters, E., \& White, H. (2013). PRISMA-Equity 2012 extension: reporting guidelines for systematic reviews with a focus on health equity. Revista Panamericana de Salud Pública, 34(1), pp. 60-67.

Williams, A. S., \& Moore, S. M. (2011). Universal Design of Research: Inclusion of Persons with Disabilities in Mainstream Biomedical Studies. Science Translational Medicine, 3(82), pp. 110.

Williams, D., \& Mohammed, S. (2009). Discrimination and racial disparities in health: evidence and needed research. Journal of Behavioral Medicine, 32(1), pp. 20-47.

Yeates, K. O., Kaizar, E., Rusin, J., Bangert, B., Dietrich, A., Nuss, K., . . Taylor, H. G. (2012). Reliable change in postconcussive symptoms and its functional consequences among children 
with mild traumatic brain injury. Archives of Pediatrics and Adolescent Medicine, 166(7), pp. 615-622.

Yeates, K. O., Swift, E., Taylor, H. G., Wade, S. L., Drotar, D., Stancin, T., \& Minich, N. (2004). Short- and long-term social outcomes following pediatric traumatic brain injury. Journal of the International Neuropsychological Society, 10(3), pp. 412-426. 